\title{
The anxiety symptoms among chronic kidney disease patients who undergo hemodialysis therapy
}

\author{
Shahrul Rahman ${ }^{1}$, Rangga Pradido \\ ${ }^{1}$ Internal Medicine Department, Muhammadiyah University Sumatera Utara, Indonesia \\ ${ }^{2}$ Faculty of Medicine, Muhammadiyah University Sumatera Utara, Indonesia
}

\begin{tabular}{l} 
Article Info \\
\hline Article history: \\
Received Apr 16, 2020 \\
Revised Jul 27, 2020 \\
Accepted Sep 12, 2020
\end{tabular}

Keywords:

Anxiety symptoms

Chronic kidney disease

Hemodialysis

\begin{abstract}
Unresolved anxiety can lead to some impact on which a person tends to have a negative assessment of the meaning of life, decreased quality of life, emotional changes such as chronic depression and psychosis disorders. The general objective in this research is to find out the symptoms of anxiety symptoms of chronic kidney disease patients undergo hemodialysis. This research employed cross sectional design. This study used nonprobability sampling type quota sampling. Sample was calculated using the Slovin formula obtained a sample size of 171 . The proportion of patient with chronic kidney disease treated with hemodialysis based on the anxiety level resulting mild anxiety (86.5\%) and moderate anxiety (13.5\%). There are symptoms of anxiety symptoms in patients with chronic kidney disease undergoing hemodialysis.
\end{abstract}

This is an open access article under the CC BY-SA license.

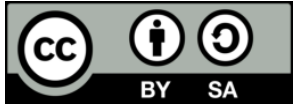

\section{Corresponding Author:}

Shahrul Rahman,

Internal Medicine Department,

Muhammadiyah University Sumatera Utara, Indonesia.

Email: shahrulrahman2@gmail.com

\section{INTRODUCTION}

Anxiety is a disorder that is triggered by the existence of a clear situation or object (from outside the individual itself), which actually does no harm. Unresolved anxiety can lead to some impact on which a person tends to have a negative assessment of the meaning of life, decreased quality of life, emotional changes such as chronic depression and psychosis disorders [1-3]. The 2013 Baseline Health Research data shows the prevalence of mental emotional disorders demonstrated by symptoms of depression and anxiety for the age above 15 years reaching around 14 million people or $6 \%$ of the total population of Indonesia. Severe mental disorders, such as schizophrenia reach approximately 400,000 people or as many as 1.7 per 1,000 population [4-6].

Chronic kidney disease (CKD) is a growing public health problem. The incidence of chronic kidney disease in many countries is 200 cases per one million populations per year. The results of a systematic review and meta-analysis conducted by Hill et al, 2016, obtained a global prevalence of CKD amounted $13.4 \%$, in Indonesia, treatment of kidney disease received second largest financing from the Health Social Security Administration Agency after heart disease [7-9]. CKD is a clinical condition characterized by irreversible decrease of renal function, so that at certain degree it will require replacement therapy for kidney function that is either hemodialysis or kidney transplantation. Criteria for CKD are kidney damage that occurs more than 3 months, in the form of structural or functional abnormalities, with or without a decrease in glomerular filtration rate (GFR). CKD may also occur when the GFR value is less than $60 \mathrm{~mL} / \mathrm{min} / 1.73 \mathrm{~m} 2$ which lasts for as long as more than 3 months, with or without kidney damage [10, 11]. 
CKD is already a public health problem. Various attempts were made to overcome various problems of chronic kidney disease such as regulating diet, dialysis and kidney transplantation. The stages of CKD are based on the remaining kidney physiology that can be measured by creatinine clearance. At stage $\mathrm{V}$ chronic kidney disease with creatinine clearance tests showing less than $15 \mathrm{~mL} / \mathrm{min} / 1.73 \mathrm{~m} 2$, it is recommended to undergo hemodialysis therapy [11-13].

Hemodialysis is a procedure in where blood is released from the patient's body and circulates in a machine outside the body called dialyzer. Hemodialysis uses the diffusion principles of dissolved substances through the semi permeable membrane [14]. In patients with CKD who undergo hemodialysis will experience psychological pressure after undergoing hemodialysis therapy. Psychological pressure that occurs in the form of anxiety, insomnia, difficulty concentrating, no appetite, feeling hopelessly exaggerated, and loss of life spirit. Psychological pressure occurs because in patients undergoing hemodialysis is very dependent on the appliance, if the patient with CKD is not undergoing therapy it will be a threat of a dead verdict that is left to wait for time. In Luana NA's research entitled Anxiety in Chronic Kidney Disease Patients Underwent Hemodialysis at the Indonesian Christian University Hospital in 2013 showed that based on HDRS scores it was known that most (77.8\%) respondents had anxiety disorders in varying degrees. A total of $29.6 \%$ of hemodialysis patients suffer from mild anxiety disorders, and $27.8 \%$ of subjects suffer from severe anxiety disorders $[15,16]$.

\section{RESEARCH METHOD}

This research was descriptive quantitative study with where data retrieval is only taken one time to find out the proportion of anxiety levels of CKD patients undergoing hemodialysis therapy at the Rasyida Kidney Speciality Hospital, Medan, Indonesia in January 2020. Data collection was carried out using beck anxiety inventory (BAI) questionnaire. BAI questionnaire will be given to patients and asked to answer the questionnaire that has been provided with interview. This study uses a sampling method that is nonprobability sampling type quota sampling, calculated using the Slovin formula obtained sample size of 171 patients. In this study the data collected is in the form of primary data. Primary data collected included: Data on anxiety levels of CKD patients at Rasyida Kidney Speciality Hospital.

\section{RESULTS}

\subsection{Result based on gender}

The results of research in patients with CKD undergoing hemodialysis at the Rasyida Kidney Speciality Hospital obtained the proportion of gender based on the level of anxiety of the respondents. Table 1 shows the anxiety level based on the gender proportions in patient with CKD undergoing with hemodialysis in Rasyida Kidney Speciality Hospital, resulting men with mild anxiety (60.2\%) women with mild anxiety $(26.3 \%)$, men with moderate anxiety $(11.1 \%)$ and women with moderate anxiety $(2.3 \%)$.

Table 1. Proportion of gender

\begin{tabular}{ccccccccc}
\hline \multirow{2}{*}{ Gender } & \multicolumn{2}{c}{ Mild anxiety } & \multicolumn{2}{c}{ Moderate anxiety } & \multicolumn{2}{c}{ Severe anxiety } & \multicolumn{2}{c}{ Total } \\
& $\mathrm{n}$ & $\%$ & $\mathrm{n}$ & $\%$ & $\mathrm{n}$ & $\%$ & $\mathrm{n}$ & $\%$ \\
\hline Men & 103 & 60.2 & 19 & 11.1 & 0 & 0 & 122 & 71.3 \\
Women & 45 & 26.3 & 4 & 2.3 & 0 & 0 & 49 & 28.7 \\
Total & 148 & 86.5 & 23 & 13.5 & 0 & 0 & 171 & 100.0 \\
\hline
\end{tabular}

\subsection{Result based on age}

The results of research in patients with CKD undergoing hemodialysis at the Rasyida Kidney Special Hospital obtained the proportion of age based on anxiety levels. Table 2 shows that the proportion of age based on the anxiety level in patients with CKD undergoing hemodialysis at the Rasyida Kidney Special Hospital, resulting patients with mild anxiety levels were mostly found in the age range 41-50 years, as many as 71 patients $(41.5 \%)$ and followed by an age range of $31-40$ years as many as 32 patients (18.7\%). Patients with moderate anxiety levels were also mostly found in the age range 41-50 years, as many as 11 patients $(6.4 \%)$ and followed by an age range of $31-40$ years, as many as five patients $(2.9 \%)$.

\subsection{Result based frequency}

Table 3 shows that the proportion of length of undergoing hemodialysis based on the level of anxiety among patients. The table describes that patients with a mild level of anxiety were most often found 
in the duration of hemodialysis $>1-3$ years as many as 49 patients $(28.7 \%)$ and followed by duration of hemodialysis $>3-5$ years as many as 38 patients $(22.2 \%)$. For patients with moderate levels of anxiety were mostly found in the duration of hemodialysis $>1-3$ years, as many as 8 patients $(4.7 \%)$ and followed by those who had been on hemodialysis $>3-5$ years and $>5-7$ years, as many as 5 patients $(2.9 \%)$.

Table 2. Proportion of age

\begin{tabular}{ccccccccc}
\hline $\begin{array}{c}\text { Age } \\
\text { (years) }\end{array}$ & \multicolumn{2}{c}{ Mild anxiety } & \multicolumn{2}{c}{ Moderate anxiety } & \multicolumn{2}{c}{ Severe anxiety } & \multicolumn{2}{c}{ Total } \\
\hline $20-30$ & 7 & 4.1 & 2 & 1.2 & 0 & 0 & 9 & 5.3 \\
$31-40$ & 32 & 18.7 & 5 & 2.9 & 0 & 0 & 37 & 21.6 \\
$41-50$ & 71 & 41.5 & 11 & 6.4 & 0 & 0 & 82 & 48.0 \\
$51-60$ & 21 & 12.3 & 1 & 0.6 & 0 & 0 & 22 & 12.9 \\
$61-70$ & 14 & 8.2 & 3 & 1.8 & 0 & 0 & 17 & 9.9 \\
$71-80$ & 3 & 1.8 & 1 & 0.6 & 0 & 0 & 4 & 2.3 \\
Total & 148 & 86.5 & 23 & 13.5 & 0 & 0 & 171 & 100.0 \\
\hline
\end{tabular}

Table 3. Proportion of frequency

\begin{tabular}{ccccccccc}
\hline Frequency & \multicolumn{2}{c}{ Mild anxiety } & \multicolumn{2}{c}{ Moderate anxiety } & \multicolumn{2}{c}{ Severe anxiety } & \multicolumn{2}{c}{ Total } \\
(length of hemodialysis) & $\mathrm{n}$ & $\%$ & $\mathrm{n}$ & $\%$ & $\mathrm{n}$ & $\%$ & $\mathrm{n}$ & $\%$ \\
\hline $1-12$ month & 19 & 11.1 & 4 & 2.3 & 0 & 0 & 23 & 13.5 \\
$>1-3$ years & 49 & 28.7 & 8 & 4.7 & 0 & 0 & 57 & 33.3 \\
$>3-5$ years & 38 & 22.2 & 5 & 2.9 & 0 & 0 & 43 & 25.1 \\
$>$ 5-7 years & 30 & 17.5 & 5 & 2.9 & 0 & 0 & 35 & 20.5 \\
$>7-9$ years & 12 & 7.0 & 1 & 0.6 & 0 & 0 & 13 & 7.6 \\
Total & 148 & 86.5 & 23 & 13.5 & 0 & 0 & 171 & 100.0 \\
\hline
\end{tabular}

\subsection{Description of anxiety symptoms in patient with CKD}

Table 4 shows that majority of patient are in the mild anxiety $(86.5 \%)$.

Table 4. Description of anxiety symptoms in patient with CKD

\begin{tabular}{ccc}
\hline Anxiety level & $\mathrm{n}$ & $\%$ \\
\hline Mild & 148 & 86.5 \\
Moderate & 23 & 13.5 \\
Total & 171 & 100.0 \\
\hline
\end{tabular}

\section{DISCUSSION}

Anxiety is a disorder that is triggered by the existence of a clear situation or object. Unresolved anxiety can cause several impacts including; decreased quality of life, emotional changes such as chronic depression and psychotic disorders. CKD is a clinical condition characterized by a decrease of renal function so that a certain degree will require kidney function replacement therapy such as hemodialysis. Hemodialysis is a procedure where bloods is removed from the patient's body and circulate in a machine outside the body called dialyzer $[1,14,17]$.

Hemodialysis uses the diffusion principles of dissolved substances through the semi permeable membrane. The results of a systematic review and meta-analysis conducted by Hill et al, 2016, found a global prevalence of CKD of $13.4 \%$. In patients with CKD who undergo hemodialysis will experience psychological stress in the form of: anxiety, insomnia, difficulty concentrating, no appetite, feeling excessive despair, and loss of life spirit. Psychological pressure occurs because in patients who undergo hemodialysis is very dependent on the appliance, if patients with CKD not undergoing the therapy, it will be a threat of a dead verdict that is left waiting for time $[9,18,19]$.

Based on the results of univariate research and analysis which amounted to 171 respondents showed that the proportion of gender based on anxiety level of CKD patients dominated by male, include 103 men $(60.2 \%)$ and 45 women $(26.3 \%)$ sufferers with mild anxiety, 19 men $(11.1 \%)$ and 4 women $(2.3 \%)$ with moderate anxiety. The results of this study are in line with the research of Riselligia Caninsti in Central Jakarta stating that subjects with anxiety levels classified as abnormal borderline amounted 7 people, which is about $23.3 \%$ with more men than women. While the subject with a normal anxiety classified 22 people, which was around $73.33 \%$, with a total of 14 men and 8 women $[20,21]$. Evidence suggests that mental health services have historically ignored the needs of female patients. In the central nervous system, estrogen can alter the concentration and availability of neurotransmitters such as serotonin and noradrenalin, as well as estrogen increases bonding from GABA agonist 
and up-regulated GABA receptors to change in depression; this induced estrogen can be a natural anti-depressant (neuroprotective) in women [22, 23]. Results of the proportion of age based on the anxiety level of patients with CKD, dominated by patients aged 41-50 years with mild anxiety as many as 71 people (41.5\%), and followed by ages 31-40 years with 32 people mild anxiety (18.7\%). Prospective studies suggest that anxiety disorders are chronic, i.e., patients may suffer from their disorder for years or decades. However, this does not mean that an anxiety disorder lasts permanently for the rest of the patient's life. Anxiety disorders start in childhood, adolescence, or early adulthood until they reach a peak in middle age, then tending to decrease again with older age. The median age of onset for anxiety disorders is 11 years [24, 25].

The results of this study showed that the proportion of the length of time undergoing hemodialysis in CKD patients was that of patients who had the most hemodialysis for $>1-3$ years amounted 49 people (28.7\%) with mild anxiety. The minimum duration for most of the anxiety disorders is $>6$ months, and the intensity is deemed to be disproportionate to the actual level of threat. Anxiety can be a diagnostic symptom in other psychiatric disorders, including depression, post-traumatic stress disorder (PTSD), and obsessive compulsive disorder, among others. Women experience pathologic anxiety at a rate approximately twice that of men. The length of undergoing hemodialysis of a CKD patient can be influenced by previous illnesses which can result in further complications, as well as experiencing a decrease in body function causing the patient in his daily life, so that the problem can cause the patient to experience anxiety. Respondents who have long undergone hemodialysis tend to have a lighter level of anxiety compared to respondents who have recently undergone hemodialysis. This is because due to the length of time someone undergoes hemodialysis, a person will be more adaptive to the dialysis unit. Previous study found the length of undergoing hemodialysis with anxiety levels obtained an $r$ value of 0.22 ; this result shows a very low correlation between the length of undergoing hemodialysis and anxiety [19, 26, 27].

Depression and anxiety are considered to be the most common end-stage renal disease-related psychological disorders, with higher prevalence and incidence rates in this population than those in the general population. In study by de Brito et al., the prevalence rates of symptoms of depression and anxiety among patients undergoing dialysis were $31.2 \%$ and $27.9 \%$, respectively, among the overall sample studied. Furthermore, depression affected approximately three times more dialysis patients than transplantation patients, whereas anxiety affected 1.5-times more dialysis patients. Anxiety refers to persistent, excessive, and unrealistic worry about everyday events or things such as financial crises, domestic issues, health care problems, and worrying about the future. Anxiety disorders are the most prevalent mental disorders that pose immense healthcare costs and a high burden of disease. Study by Dziubek et al., revealed that nearly 68\% of respondents in Dialysis Patients had symptoms of depression. Apart from depression, patients also struggled with anxiety disorders. Elevated levels of anxiety were observed in approximately $50 \%$ of patients [28-30].

The limitations of researchers in conducting research on the description of anxiety symptoms in CKD patients undergoing hemodialysis therapy at the Rasyida Kidney Specialty Hospital are researchers not aware of any other contributing factors of anxiety. These factors are such as family support, socio-economic factors, co morbidities, and other factors that may be the cause of anxiety in patients with CKD undergoing hemodialysis therapy.

\section{CONCLUSION}

The majority of patients with CKD undergoing hemodialysis at the Rasyida Kidney Special Hospital were in mild anxiety (86.5\%). The anxiety level based on the gender proportions in patients with CKD undergoing with hemodialysis in Rasyida Kidney Speciality Hospital, resulting men with mild anxiety (60.2\%). The anxiety level based on the age proportions in patients with CKD undergoing hemodialysis at the Rasyida Kidney Special Hospital, resulting patients at the age of 41-50 years old with mild anxiety (41.5\%). The proportion of length of undergoing hemodialysis based on the level of anxiety in patients with CKD who undergoing hemodialysis at the Rasyida Kidney Special Hospital, resulting mild anxiety over long period of hemodialysis $>1-3$ years $(28.7 \%)$.

Researchers are expected to find any other contributing factors of anxiety such as family support, socio-economic factors, co morbidities that may be the cause of anxiety in patients with CKD undergoing hemodialysis therapy. Researchers are expecting to other clinicians to be able to provide education about physiological health to the patient.

\section{REFERENCES}

[1] Bystritsky A, Khalsa SS, Cameron ME, Schiffman J., "Current diagnosis and treatment of anxiety disorders," Pharmacy and Therapeutics, vol. 38, no. 1, pp. 30-57, 2013.

[2] Crocq MA., "A history of anxiety: from Hippocrates to DSM," Dialogues Clin Neurosci, vol. 17, no. 3, pp. 319-325, 2015.

[3] Grupe DW, Nitschke JB., "Uncertainty and anticipation in anxiety: an integrated neurobiological and psychological perspective," Nat Rev Neurosci. vol. 14, no. 7, pp. 488-501, 2013.

Int. J. Public Health Sci, Vol. 9, No. 4, December 2020: $281-285$ 
[4] Lawrence D, Johnson S, Hafekost J., et al., "The Mental Health of Children and Adolescents" Report on the second Australian Child and Adolescent Survey of Mental Health and Wellbeing. Department of Health, Canberra, 2015.

[5] Octavia S, Asih SR, Jaya ES. "Does negative-self-schema link the relationship between childhood trauma and psychotic symptoms in a community sample of Indonesians?," Konselor, vol. 8, no. 3, pp. 65-73, 2019.

[6] Reong AS, Astuti RP., "Stigma in Family Patients Who Have a Psychiatric Disorder: A Systematic Review," Jurnal Ners, vol. 14, no. 3si, pp. 86-90, 2019.

[7] Fung E, Kurella Tamura M., "Epidemiology and Public Health Concerns of CKD in Older Adults," Adv Chronic Kidney Dis., vol. 23, no. 1, pp. 8-11, 2016.

[8] Levey AS, Atkins R, Coresh J., et al., "Chronic kidney disease as a global public health problem: Approaches and initiatives-a position statement from Kidney Disease Improving Global Outcomes,” Kidney International, vol. 72, no. 3, pp. 247-259, 2007.

[9] Hill NR, Fatoba ST, Oke JL, et al., "Global Prevalence of Chronic Kidney Disease-A Systematic Review and MetaAnalysis," PLoS One, vol. 11, no. 7, p. e0158765, 2016.

[10] Chapter 1: Definition and classification of CKD. Kidney Int Suppl (2011). vol. 3, no. 1, pp. 19-62, 2013.

[11] Vaidya SR, Aeddula NR, “Chronic Renal Failure,” Treasure Island (FL): StatPearls Publishing, 2020.

[12] Sandilands EA, Dhaun N, Dear JW, Webb DJ., "Measurement of renal function in patients with chronic kidney disease," Br J Clin Pharmacol, vol. 76, no. 4, pp. 504-515, 2013. doi:10.1111/bcp.12198

[13] Vassalotti JA, Centor R, Turner BJ, et al., "Practical Approach to Detection and Management of Chronic Kidney Disease for the Primary Care Clinician,” The American Journal of Medicine, vol. 129, pp. 2, pp. 153-162, 2016.

[14] Vadakedath S, Kandi V., "Dialysis: A Review of the Mechanisms Underlying Complications in the Management of Chronic Renal Failure," Cureus., vol. 9, no. 8, p. e1603, 2017.

[15] De Sousa A., "Psychiatric issues in renal failure and dialysis," Indian J Nephrol. vol. 18, no. 2, pp. 47-50, 2008.

[16] Luana NA, Sahala P, Joyce VML, Ika C., "Anxiety in Patients with Chronic Kidney Disease Underwent Hemodialysis at the Indonesian Christian University Hospital (Kecemasan pada Penderita Penyakit Ginjal Kronik yang Menjalani Hemodialisis di RS Universitas Kristen Indonesia)," M Med Indones., vol. 46, no. 3, pp. 151-156, 2012.

[17] Iverach L, Menzies RG, Menzies RE., "Death anxiety and its role in psychopathology: Reviewing the status of a transdiagnostic construct," Clinical Phycology Review, vol. 34, no. 7, pp. 580-593, 2014.

[18] John JF, Thomas VJ., "The Psychosocial Experience of Patients with End-Stage Renal Disease and Its Impact on Quality of Life: Findings from a Needs Assessment to Shape a Service. International Scholarly Research Notices, vol. 2013, pp. 1-8, 2013.

[19] Cohen SD, Cukor D, Kimmel PL., "Anxiety in Patients Treated with Hemodialysis," Clinical Journal of The American Society of Nephrology, vol. 11, no. 12, pp. 2250-2255, 2016.

[20] Mazzone L, Ducci F, Scoto MC, Passaniti E, D'Arrigo VG, Vitiello B., "The role of anxiety symptoms in school performance in a community sample of children and adolescents," BMC Public Health, vol. 7, no. 347, 2007.

[21] Caninsti R., "Anxiety and Depression in Patients with Chronic Kidney Failure Underwent Hemodialysis Therapy (Kecemasan dan Depresi pada Pasien Gagal Ginjal Kronis yang Menjalani Terapi Hemodialisis)," Jurnal Psikologi Ulayat. vol. 1, no. 2, pp. 207-222, 2016.

[22] Archer M, Lau Y, Sethi F., "Women in acute psychiatric units, their characteristics and needs: a review," BJPsych Bulletin, vol. 40, no. 5, pp. 266-272, 2016.

[23] Gilburt H, Rose D, Slade M., "The importance of relationships in mental health care: a qualitative study of service users' experiences of psychiatric hospital admission in the UK," BMC Health Services Research, vol. 8, no. 92, 2008.

[24] Fiske A, Wetherell JL, Gatz M., "Depression in older adults," Annu Rev Clin Psychol., vol. 5, pp.363-389, 2009.

[25] Bandelow B, Michaelis S., "Epidemiology of anxiety disorders in the 21st century," Dialogues Clin Neurosci., vol. 17, no. 3, pp. 327-335, 2015.

[26] Goh ZS, Griva K. "Anxiety and depression in patients with end-stage renal disease: impact and management challenges - a narrative review," Int J Nephrol Renovasc Dis., vol. 11, pp. 93-102, 2018.

[27] Gerogianni G, Polikandrioti M, Babatsikou F, et al. "Anxiety-Depression of Dialysis Patients and Their Caregivers," Medicina (Kaunas), vol. 55, no. 5, pp. 168. 2019.

[28] de Brito DCS, Machado EL, Reis IA, do Carmo LPF, Cherchiglia ML. "Depression and anxiety among patients undergoing dialysis and kidney transplantation: a cross-sectional study," Sao Paulo Med J, vol. 137, no. 2, pp. 137-47, 2019.

[29] Dziubek W, Kowalska J, Kusztal M, et al. "The Level of Anxiety and Depression in Dialysis Patients Undertaking Regular Physical Exercise Training-a Preliminary Study,” Kidney Blood Press Res, vol. 41, pp. 86-98, 2016.

[30] Alqarni AM, Alghamdi EA, Alaqil NA, et al. "Prevalence of Anxiety and Depression and its Related Influencing Factors among Patients with End-stage Renal Disease on Hemodialysis in Al-Kharj, Saudi Arabia," Int J Med Res Health Sci., vol. 8, no. 1, pp. 55-62, 2019. 